\title{
"Urban Versus Regional Divide: Comparing and Classifying Digital Divide”
}

\author{
Lead Author: Enrico Ferro ${ }^{1}$, \\ Coauthors: Marco Cantamessa ${ }^{2}$, and Emilio Paolucci ${ }^{2}$ \\ ${ }^{1}$ Istituto Superiore Mario Boella (ISMB), Via Boggio 61, 10138 Turin, Italy \\ Tel: +39011 2276201, Fax: + 390112276299 \\ www.enricoferro.com \\ ${ }^{2}$ Politecnico di Torino (POLITO), Cso Duca degli Abruzzi 24,10129, Turin, Italy \\ Tel: +390115647223, Fax: +390115647299 \\ \{marco.cantamessa, emilio.paolucci\}@polito.it
}

\begin{abstract}
This paper presents a comparative study on digital divide between a region and its main metropolitan area. The exercise shows how barriers to technology access and usage may vary in terms of both nature and intensity. The paper also proposes a taxonomy of the different types of digital divides that may be present inside a region.
\end{abstract}

\section{Introduction}

In recent years, the issue of digital divide has attracted significant interest from both scientists and policy markers. Many papers and reports have been published trying to quantify and describe the phenomenon in terms of who is affected and how.

Researchers that have heretofore dealt with the issue of digital divide may be classified into two main categories. On the one side, there are those that believe digital divide to be a physiological delay inherent in the diffusion of technologies among different geographic areas and social groups [1], [2]. These researchers share the view that digital delays do not require the intervention of public administration since they will eventually be solved by the market.

On the other side, there are researchers that see digital divide as a source of social inequality that mirrors the unbalanced situation in terms of opportunities and quality of life present at global level. For this reason they claim a public intervention to be necessary since the market has shown not to be able to bridge a gap that is profoundly rooted in the structure of society [3], [4].

In spite of the very different views and opinions emerged about the importance and the magnitude of the digital divide in both the short and the long term, a general agreement has been reached on the actual presence of a gap in terms of possibilities and opportunities between people who have access to information and people who do not.

M. Böhlen et al. (Eds.): TCGOV 2005, LNAI 3416, pp. 81-90, 2005.

(C) IFIP International Federation for Information Processing 2005 
The aim of this paper is not to discuss the importance of digital divide, but simply to raise the awareness of policy makers about some of the aspects that should be kept in due account when assessing its possible presence in a region. It is our firm belief that, regardless of its importance, digital divide represents an issue that may potentially jeopardize the homogenous diffusion and development of the information society in a territory and as such it must be carefully monitored and wisely managed by local and regional governments.

\section{Context: “The Info-Society Regional Observatory”}

The results presented in the following paper are based on the data collected by the Regional Observatory on the Information Society of the Mario Boella Institute. On a yearly basis, the above-mentioned observatory collects data about technology adoption and usage among the main socio-economic actors present on the territory.

The comparative exercise presented below has been carried out using data collected from citizens while the taxonomy proposed in the second part of the paper has been created using the data collected from citizens, municipalities and enterprises.

\section{Objectives}

The objectives of the paper at hand are mainly two:

1. To help policy makers understand what types of policies may yield the best returns in terms of the Information Society diffusion. Objective that will be pursued by investigating, through a comparative analysis, the context dependency of factors contributing to the creation of digital gaps in areas with similar socio-economic systems.

2. To suggest a taxonomy of different types of digital divide aiming at pointing out the complementary relationship between demand and offer aspects. The acknowledgement of presence of this relationship may represent a key interpretative tool for policy makers in order to create a systemic view of the phenomenon.

\section{Methodology}

As already mentioned, for the purposes of this paper the data collected by the Regional Observatory on the Information Society of the ISMB was used.

For the identification of the digital divide determinants, two stratified samples of citizens were generated to compare the digital divide present in the region with the one present in the main metropolitan area located in the same region. As it may be noticed from table 1, interviews were distributed as follows: 1000 in the Piedmont 
region and 700 in the city of Turin. The total number of interviews was thus 1700 out of a total population of about 4.2 million inhabitants.

Table 1. Sample Breakdown

\begin{tabular}{|l|c|c|}
\hline \multicolumn{1}{|c|}{} & \multicolumn{2}{c|}{ SAMPLING } \\
\hline \multicolumn{1}{|c|}{ Area } & Sample Size & Population \\
\hline Turin & 700 & 900,987 \\
\hline \hline Piedmont & 1000 & $3,313,690$ \\
\hline \hline Total & 1700 & $4,214,677$ \\
\hline
\end{tabular}

The variables adopted for the stratification of the sample were: age, gender and size of town of residence. The methodology used for the data collection was CATI (Computer Aided Telephone Interviews).

As per the analysis, the data set used included Boolean variables (broadband adoption and usage) and ordinal categorical variables (explanatory variables). By adopting log-linear models it was possible to identify which categories (i.e.: income/age/education ranges) had a statistically significant probability not to be broadband adopters/users. These probabilities were calculated using odds ratios that are a common measure of association among variables.

From a policy maker point of view this is an extremely interesting result since it allows to single out the population groups that should be targeted in the process of policy design.

Finally, for the creation of the digital divides taxonomy we included the data collected from also enterprises and public administrations in order to have a solid basis of observations representing the most important aspects of the phenomenon.

\section{Urban Versus Regional Divide}

In this section of the paper, we are going to present the results of a comparative study between the Piedmont region and the city of Turin in terms of digital divide. The exercise has been carried out with the intent to investigate whether and how the determinants of digital divide may vary in terms of nature and intensity even between areas belonging to the same region.

Due to length constrains, we decided to focus our analysis on two variables. Nevertheless we made sure to include both access and usage aspects. The first aspect investigated was the adoption of broadband connections ( $\geq 640 \mathrm{kbs})$ among households. The segmentation variables used were: income and number of people in the household. Explanatory variables such as age, education and gender were not used in the analysis of this aspect since the adoption of an Internet connection is a decision influenced by the family composition rather then just some specific characteristics of the person answering the telephone interview. 


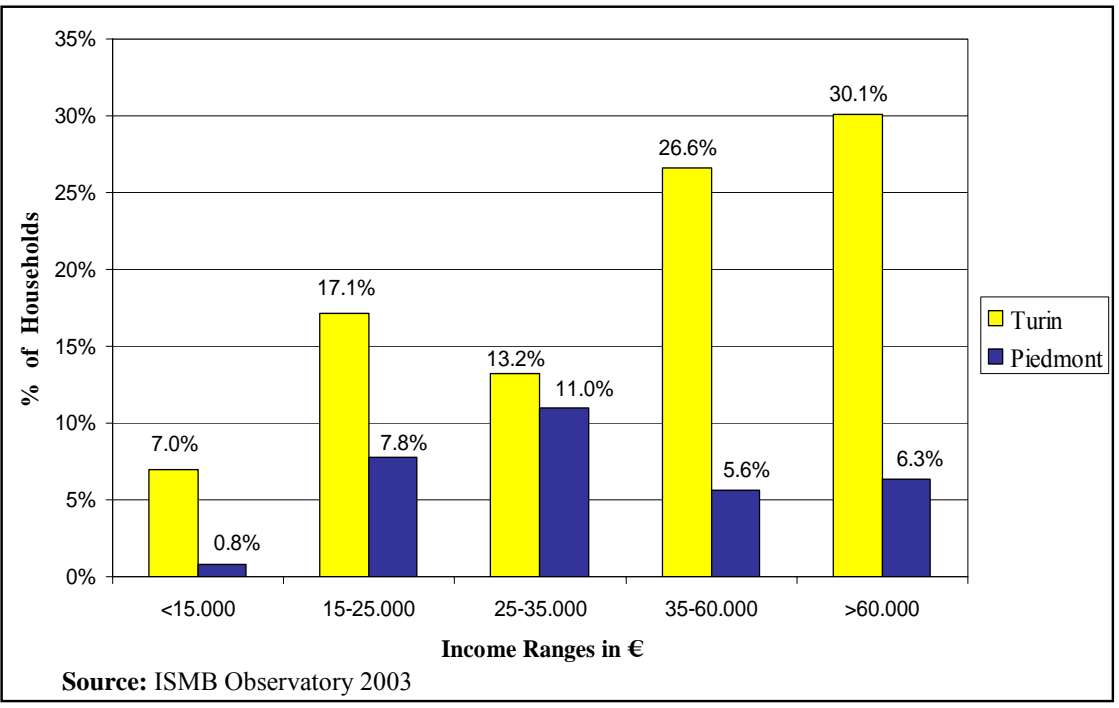

Fig. 1. Households with a Broadband Connection by Income

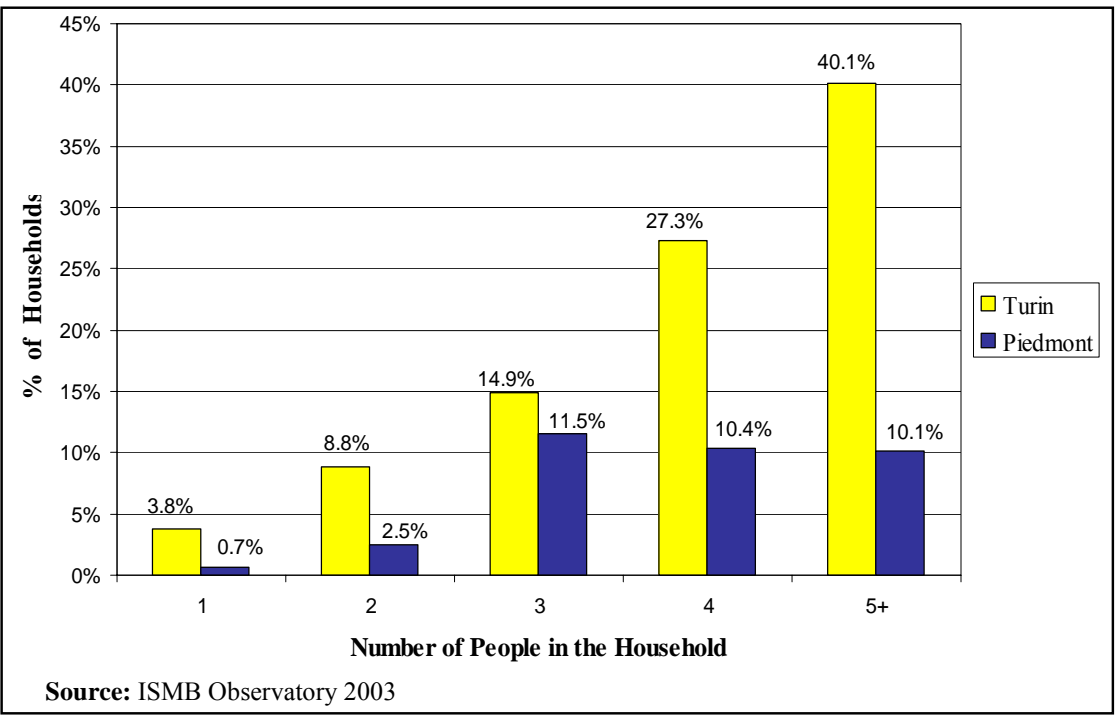

Fig. 2. Households with a Broadband Connection by Size

As it may be noticed by looking at figure 1 and 2 different scenarios may be depicted for the two areas taken into consideration. In Turin both income and family size seem to be important adoption drivers, while the situation is not equally clear in 
Piedmont. In order to deepen the understanding of the impact of each segmentation variable, a multivariate analysis was conducted allowing to isolate the effect of income and household size on adoption.

In the log-linear model design, income and family size were set as explanatory variables while broadband adoption was set as outcome.

In Turin, the analysis showed that small and low income households are more likely not to have a broadband connection. (Odds ratios of not owning a broadband connection are respectively 5.39 for households with a yearly net income lower than $15,000 €, 6.31$ for households with one member and 3.59 for households with two members).

In Piedmont, instead, the situation looks quite different. Income does not exert a statistically significant influence on the adoption of broadband connections while families with one and two members have odd ratios of not having a broadband connection that are respectively 2.4 and 3.7 times higher than the ones found for the city of Turin.

It is also interesting to note that in Turin the odds ratio of one member households not to have broadband connection is 1.76 times higher than those of a household with two members, while in Piedmont are only 1.1 higher. As a caveat, it must be said that the validity of odds ratio comparison holds as long as all the other independent variables are kept constant.

From this first part of the analysis it is already possible to observe some significant differences between the two areas. From a policy maker point of view, being able to identify families with a yearly net income lower than $15.000 €$ as potential information outcasts represents an important piece of information that could be used to design more effective and better targeted support policies.

Moreover, the fact that income plays a role in broadband adoption in the main city where the infrastructures are available, but it does not in the rest of the region where digital highways are scarce could suggest that an approach simply based on fostering the diffusion of infrastructures will not be enough to contrast the potential diffusion of digital divide.

As far as usage is concerned, the variable used in the analysis was: regular Internet usage, defined as access on at least a weekly basis.

The comparative descriptive statistics presented from figure 3 to 5 provide a first picture of the possible relationships between regular Internet usage and three socioeconomic variables: age, education and gender.

At a first glance, the situation present in both areas seems to be similar, but at a closer look reality may be quite different. As already stated, descriptive statistics does not allow to separate the influence of each variable. We thus adopted a multivariate approach again, finding some interesting results.

The log-linear model was designed as follows: regular Internet usage was set as response variable while age, gender and education were used as explanatory variables.

By looking at the results produced by the application of the model at the two areas, it emerged that in Turin the width of digital gaps is wider than in Piedmont. In fact, although in both areas age and education are positively correlated with regular Internet usage, in Turin the odds ratio not to be a regular Internet user of a person between 45 to 54 years old is 9.5 times higher than that of a person between 16 and 24. In Piedmont, instead, people with an age between 45 and 54 have an odds ratio 


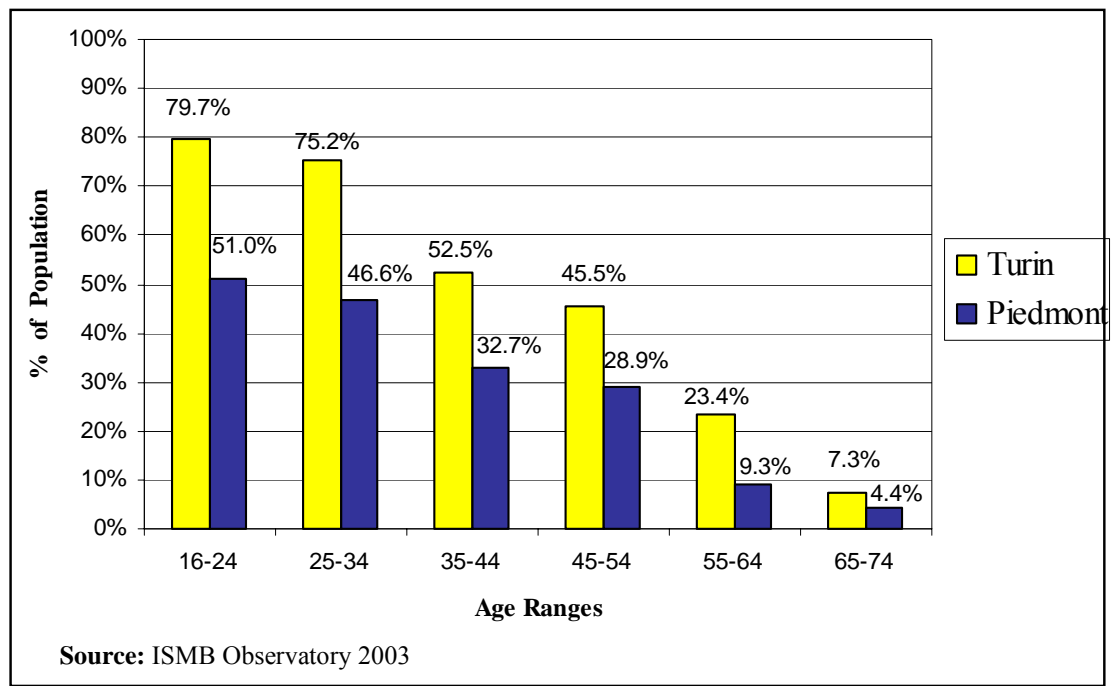

Fig. 3. Regular Internet Users by Age

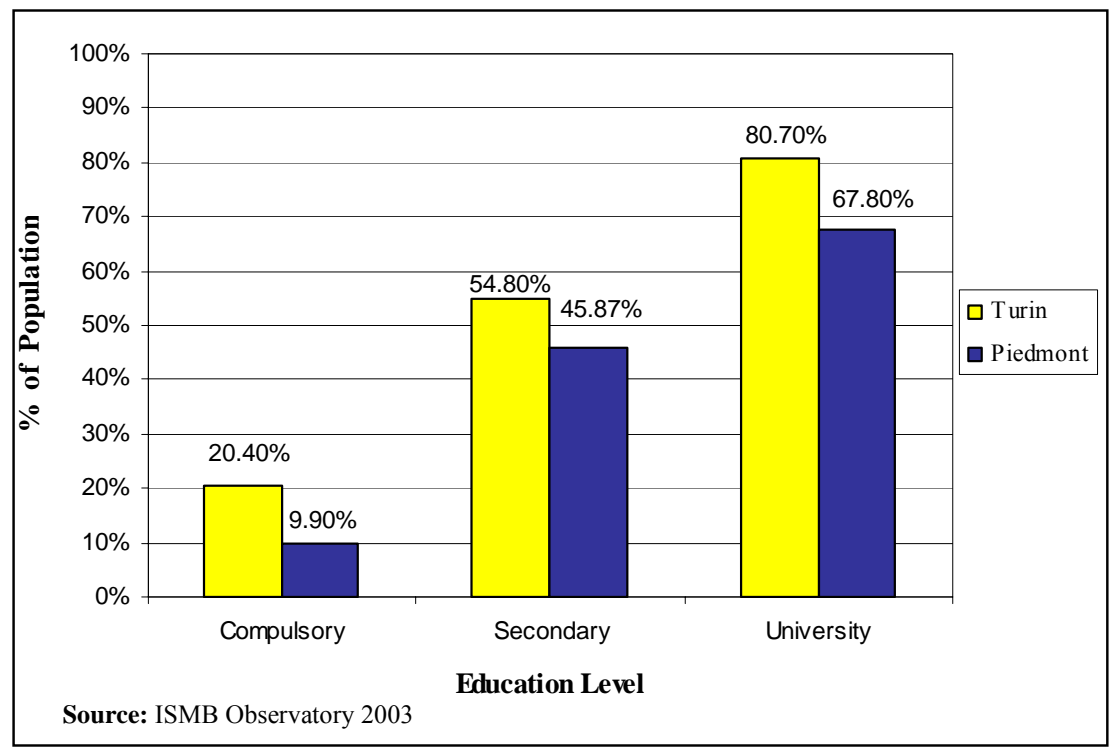

Fig. 4. Regular Internet Users by Education Level

not be a regular internet user that is only 2.5 times higher than that of people between 16 and 24. This, in simple terms, means that the divide present in terms of usage between young and mature people in Turin is considerably wider than in Piedmont. 


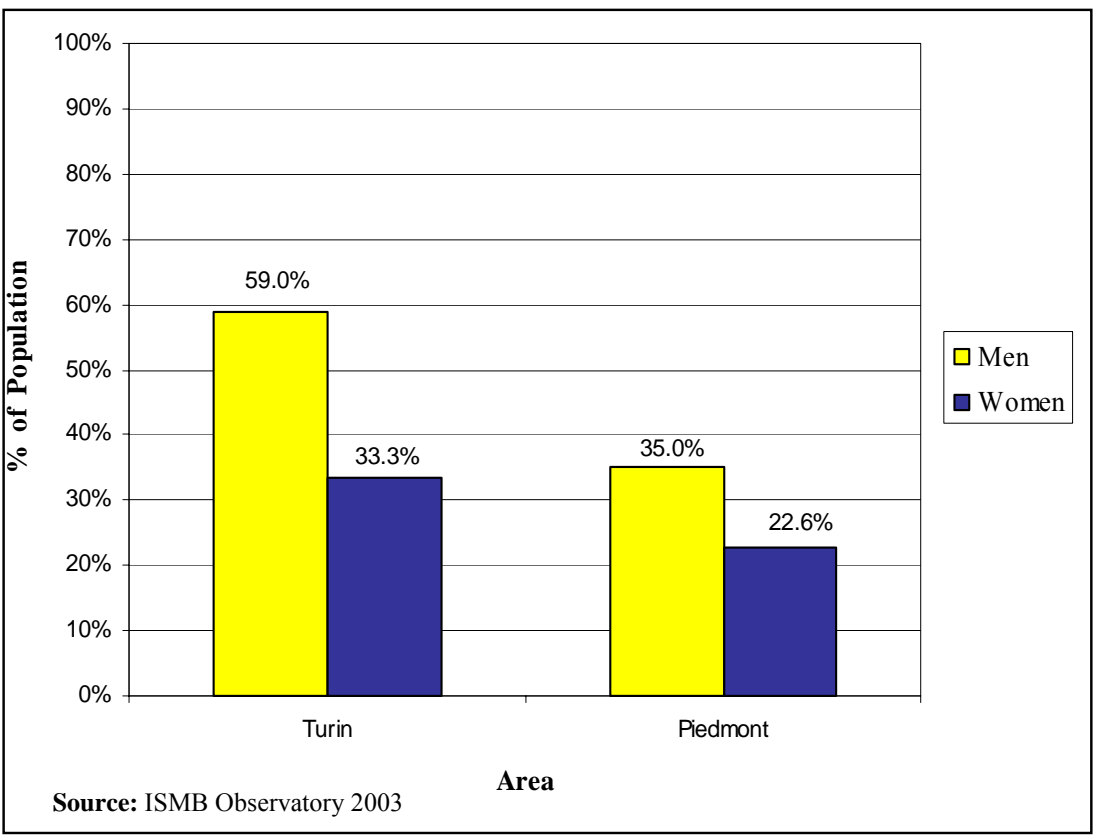

Fig. 5. Regular Internet Users by Gender

As far as gender is concerned, some differences may be found as well. In Turin, women have an odds ratio not to be regular internet users that is twice as high as that of women living outside the main city.

Finally, taking into consideration education, the model mainly confirms what may be noticed from the descriptive statistics. In other words, people with a compulsory education in Turin are twice as less likely to be regular Internet users than those living in the rest of the region.

The correlation between age, gender, education and Internet usage, in itself does not represent a novelty. What may be considered an interesting result, instead, is the fact that digital divide seems to be more severe in areas with higher penetration levels. From a policy maker stand point this represent a challenge since, it reinforces the idea that policies should not only foster infrastructure diffusion but also account for socioeconomic divides that arise as the level of adoption increase.

\section{Digital Divide Taxonomy}

In this final section of the paper, we present a taxonomy that was generated from the observation of different types of digital divide.

The analysis carried out in the first part of this paper showed digital divide as a multifaceted issue that requires articulated solutions. For this reason, the identification of its main dimensions is felt to be an essential step toward the definition of effective policies. 
The classification below does not have the ambition to be exhaustive, but should be considered as a first attempt to provide an explicit framework to the different types of digital divide. In particular, it aims to highlight the correlation between demand and offer related aspects.

\begin{tabular}{|c|c|c|}
\hline \multirow{4}{*}{ 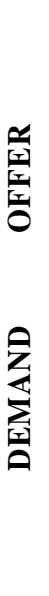 } & \multicolumn{2}{|c|}{ DIGITAL DIVIDE TAXONOMY } \\
\hline & $\begin{array}{l}\text { 1. Availability of PCs and Internet } \\
\text { connections in schools and public places } \\
\text { 2. Diffusion of WAI compliant websites }\end{array}$ & $\begin{array}{l}\text { 1. Lack of e-Government service } \\
\text { provisioning in small municipalities } \\
\text { 2. Availability of broadband networks } \\
\text { outside metropolitan areas }\end{array}$ \\
\hline & $\begin{array}{l}\text { 1. Gap associated to age, gender, } \\
\text { education and income } \\
\text { 2. Gap associated to enterprise size, sector } \\
\text { of activity and type of management }\end{array}$ & $\begin{array}{l}\text { 1. Lower penetration of PC and Fast Internet } \\
\text { connections in rural vs. metropolitan areas } \\
\text { 2. Less training and lower ICT usage in } \\
\text { small Public Administrations }\end{array}$ \\
\hline & $\begin{array}{l}\text { INTRA-MUNICIPAL } \\
\text { (Social Classes) }\end{array}$ & $\begin{array}{l}\text { INTER-MUNICIPAL } \\
\text { (Geographic Areas) }\end{array}$ \\
\hline
\end{tabular}

Fig. 6. Digital Divide Taxonomy

Figure 6 represents a two by two matrix classifying the different types of digital divides that may be found inside a single region. Along the vertical axis it is possible to distinguish between demand and offer of ICT related products or services. Along the horizontal axis, instead, a distinction is made between gaps present among geographic areas (i.e. urban vs. rural areas, big municipalities vs. small, etc.) and those that are present inside a single municipality. In the case of population, these gaps may be attributed to factors such as income, education, gender. In the case of enterprises, to size, sector of activity, type of management, etc.

The classification work carried out may be considered to be useful for the following reasons. First of all, it shows that digital divide is not a monolithic concept but rather a multifaceted phenomenon determined by the interaction of a set elements with specific features. This view suggests that policies should be designed coherently with the characteristics of the digital divide they are aiming to bridge and that a onesize-fits-all approach will most likely fail in producing effective results.

Secondly, the classification highlights the interdependency relationship between demand related and offer related gaps. Often times, in fact, digital divide is regarded in its entirety as one of the main motivations of slow and heterogeneous diffusion of ICT technologies. Rarely, instead, these motivations have been presented as a combination of demand and offer related causes.

Finally, the classification shows that investment choice may have a tremendous impact on results obtained. Investing in policies aiming at reducing offer related 
divides may in fact represent a wiser choice since it has an indirect impact on demand related divides as well. To exemplify, an investment aimed at increasing the availability of PCs in schools will also have a positive impact on demand related gaps due to socio-economic variables.

\section{Conclusions}

From the comparative exercise carried out, the main result that emerged was that in the two areas considered, the barriers to access and usage may differ both in terms of nature and intensity. In fact, it showed that the impact of socio-economic variables on both technology adoption and usage seems to be more severe in the city of Turin, where penetration rates are higher and the broadband infrastructure coverage is complete. This suggests that just investing in physical infrastructures to connect rural areas will only partially solve the issue of digital divide, since it would simply shift the problem from a geographical to a socio-economic sphere.

Moreover, public investments in network infrastructures entail a number problems and risks. Firstly, technological neutrality, although auspicated by EU regulations, is next to impossible to achieve in practice. As a consequence, this type of investments requires a technological choice that is bound to create market perturbations. Secondly, the high level of red tape involved coupled with the high pace of technological innovation, may render the technology chosen obsolete even before its application.

A further confirmation that investments in infrastructures alone do not yield good results may be found in the data about coverage and adoption of broadband services in Piedmont (respectively $70 \%$ and $9.1 \%$ ).

At this point, a legitimate question could arise: what type of intervention would then be necessary? In our opinion, policies aimed at fostering the level of adoption where infrastructures are already available may prove to be more effective since they produce positive effects on both demand and offer related aspects. On the former, the increase of users produces positive network externalities. On the latter, instead, the increase of the adopters' percentage contributes to reduce the threshold of potential customers that municipalities need to meet in order to be reached by telecom operators. Moreover, it also represents an incentive for application providers to increment the amount of content produced.

Concluding, the multidimensional approach adopted should account for the different types of divides present on the territory. As a matter of fact, the choice of which gap to bridge may actually results to be strategically important in order to maximize the impact of the investment on the entire system.

\section{References}

1. Adriani F., Becchetti L. (2003), "Does the Digital Divide Matter? The role of ICT in cross-country level and growth estimates". CEIS Tor Vergata.

2. Benjamin M., (2001) "Re-examining the Digital Divide", Internet and Telecom Consortium, MIT

3. Chin M.D, Fairlie R.W., (2004) "The determinants of the Global Digital Divide: A Cross-Country Analysis of Computer and Internet Penetration" Economic Growth Center Yale University 
4. Cole J.I., et al., (2004) “The Digital Future Report” USC Center for the Digital Future.

5. Christie I and Perry H (1997) "Wealth and poverty of networks: tackling social exclusion" Demos, London

6. Foley P., (2004), "Does the Internet Help to Overcome Social Exclusion" International Journal of eGovernment Vol. 2 Issue 2 pp.139-146

7. Kim H., Moon J., Yan S., (2004), "Broadband Penetration and Participatory Politics: South Corea Case", HICSS conference

8. Norris P., (2000) "World Wide Digital Divide: Infopoverty, the Internet and Development", Johnn F. Kennedy School of Government, Harvard.

9. Peter K. YU., (2002), "Bridging the Digital Divide: Equality in the Information Age" Cardozo Law School. http://ssrn.com/abstract_ID=309841

10. Piazolo D. (2001), “The Digital Divide” CESifo Forum 2001, Vol.2 No. 3, 29-34.

11. Prieger J.E., (2001), "The Supply Side of the Digital Divide: Is There Redlining in the Broadband Internet Access Market?” http://ssrn.com/abstract_ID=309841

12. Xavier P., (2002) "Bridging the digital divide: issues and policies in OECD countries", OCSE, Paris. 